\title{
Critical Incidents of Growth in Nordic eHealth Service Start-Ups
}

\author{
MARTTI SAARELA \\ University of Oulu, Finland \\ martti.saarela@oulu.fi \\ DANIEL ÖRTQVIST \\ Lulea University of Technology, Sweden \\ daniel.ortqvist@ltu.se
}

ANNA-MARI SIMUNANIEMI

University of Oulu, Finland

anna-mari.simunaniemi@oulu.fi

MATTI MUHOS

University of Oulu, Finland

matti.muhos@oulu.fi

Digitalisation can revolutionise healthcare delivery and provide new business opportunities for innovative start-ups. Start-up businesses in the healthcare service sector are a promising source of new employment and innovations. The start-up stage is the most critical period for the survival of a business, as decisions made during the early stages have a definitive influence on success. This study seeks to clarify the early development of eHealth service start-ups. To summarise the research problem, the authors ask the following question: What are the critical incidents related to the early development of eHealth service start-ups? The units of analysis in this study are 14 Nordic eHealth service start-ups located in Sweden and Finland. The Critical Incident Technique (сіт) and semi-structured interviews were applied for data collection. The results are of interest to the public sector, which plays an essential role in healthcare as a service producer, but also as a creator of the business conditions of and opportunities for small businesses.

Key words: eHealth, start-up, critical incidents, Finland, Sweden https://doi.org/10.26493/1854-4231.12.115-131

\section{Introduction}

Due to obesity, aging populations and the increasing prevalence of chronic diseases, European healthcare systems are facing an increased social and healthcare demand (Pinto and Baracsi 2012; Van Limburg et al. 2011). This growing demand has led to a dramatic 
increase in health spending in many nations, as this sector constitutes a significant percentage of the gross domestic product (GDP) (Pinto and Baracsi 2012). In 2013, health spending accounted for approximately $9 \%$ of the GDP in OECD countries (OECD 2015). In addition, healthcare systems have faced considerable challenges in the implementation and dissemination of new initiatives, despite the general perception that healthcare organisations are among the most knowledge-rich and research-based organisations (Barnett et al. 2011; Berwick 2003).

Increased healthcare service demands and economic challenges facing an already overworked healthcare system have led to the urgent need for effective, scalable, sustainable and innovative healthcare services (Rocha et al. 2013; Barnett et al. 2011; Pinto and Baracsi 2012). Technology development and digitalisation are seen as key responses to the increased requirements of cost effectiveness and quality improvements in healthcare systems and services (European Commission 2012; Agarwal et al. 2010); digitalisation can even revolutionise healthcare delivery (Parente 2000). In the USA, the digital health scene is already becoming highly dynamic, with numerous incubators and investors beginning to specialise in healthcare. The question is how high-growth companies in Europe can scale up quickly and globally to have the impact needed to tackle challenges in the healthcare industry (Pinto and Baracsi 2012). From the business perspective, digitalisation means opportunities for getting involved in areas as diverse as personalised medicine and advanced analytics, as well as mobile technologies and applications (European Commission 2012).

Although the market potential of eHealth services is strong, businesses are not currently realising the full benefits of digital services (European Commission 2015). There is an urgent need for innovations in healthcare practice and delivery in large healthcare markets (Chowdhury 2012). The concept of eHealth has been increasingly gaining the attention of researchers from different disciplines, including the medical, public health, technological and innovation management fields (Chen, Wen, and Yan 2014). According to the European Commission (2012), eHealth provides patients with more health-related information, facilitates increased involvement in health, improves access to health advice and treatment and allows people to monitor their health and well-being online through such devices as smartphones.

Due to innovations and competitive pressure produced by startups, increasing evidence suggests they are major factors in eco- 
nomic development (Samuelsson and Davidsson 2009). Innovation is identified as a promising strategy for new start-ups. Because they can be more flexible and agile than established small and mediumsized enterprises, they are pioneer innovations and able to operate under conditions of limited competition for a prolonged period (Rosenbusch, Brinckmann, and Bausch 2011). Moreover, start-ups can be potential sources of new jobs and significant promoters of new service innovations in the healthcare service sector. Nanda and Rhodes-Kropf (2013) state that radical innovations require an orientation towards experimentation and a willingness to fail. According to Lumpkin and Dess (1996), autonomy, innovativeness, risk taking, proactiveness and competitive aggressiveness are factors that may all be present when a company enters the market. Nooteboom (1994) states that small firms have better behavioural qualities than larger firms to translate technology into a variety of new technologyproduct-market combinations.

Small companies or new entrants may be willing to accept greater risks than may be large firms. It is well known that death rates in early age are much higher than those in later are (Freeman, Carroll, and Hannan 1983). This hypothesis is called 'liability of newness,' as coined by Stinchcombe (1965), and it assumes higher risks of failure for young organisations compared to old ones. According to Pinto and Baracsi (2012), only the best ideas survive the so-called 'valley of death,' the financial period during which new start-ups begin activities to turn their ideas into marketable products or services.

The start-up stage is the most critical period for a company's survival, as incidents, coincidences and decisions made during the early stages of growth have a definitive influence on a company's productivity and success. Understanding the activities of new businesses is clearly an interesting field of academic study (Haltiwanger, Jarmin, and Miranda 2013). The early development of eHealth service startups has not been broadly studied. Therefore, this study highlights the critical incidents related to the development of eHealth service start-ups from the entrepreneurs' viewpoints in the Nordic context. To meet the aim of this study, the authors ask the following research question: What are the critical incidents related to the early development of eHealth service start-ups?

The results of this study may be used effectively in new eHealth service businesses to predict managerial challenges during the early stages of growth. In addition, intermediary organisations, such as public advisory services, can utilise the results to improve their services. 
TABLE 1 Main Characteristics of Case Companies

\begin{tabular}{lllll}
\hline$(1)$ & $(2)$ & $(3)$ & $(4)$ & $(5)$ \\
\hline A & Sweden & 2014 & 5 & Management and systems consultant \\
B & Sweden & 2015 & 4 & Cloud service \\
C & Sweden & 2011 & 4 & Accessories for mobiles \\
D & Sweden & 2014 & 7 & Online consultation system \\
E & Sweden & 2015 & 2 & Online healthcare \\
F & Sweden & 2011 & 6 & Communication system services \\
G & Finland & 2013 & 1.5 & Mobile application-related wellbeing \\
H & Finland & 2014 & 3.5 & Health data processing \\
I & Finland & 2014 & 3.5 & On-line wellbeing \\
J & Finland & 2008 & 4 & Product-related MedTech service \\
K & Finland & 2010 & 5 & Product-related MedTech online service \\
L & Finland & 2012 & 4 & Software-based wellbeing services \\
M & Finland & 2014 & 2 & Self-care user interface \\
N & Finland & 2012 & 6 & Product-related wellbeing service \\
\hline
\end{tabular}

Notes Column headings are as follows: (1) case, (2) country, (3) established, (4) number of people, (5) service description.

\section{Method}

According to Neergaard and Ulhoi (2007), entrepreneurship research is context-specific, and it should be focused on entrepreneurs' behaviours and the real problems with which they must cope. Qualitative methods are used when the aim is to make entrepreneurs' stories visible and to understand enterprises in their natural context. Because each enterprise's circumstances are unique, the type of incident, context, strategy and outcomes cannot be generalised directly to other businesses.

In this multiple-case study, 14 start-ups in Sweden and Finland are analysed. According to Yin (1988), a multiple-case study design has a distinct advantage compared to a single-case design, as evidence is considered more compelling and the study design is therefore regarded as more robust. The empirical data for this study are based on semi-structured thematic interviews among start-up entrepreneurs or managers. The cases were analysed using the Critical Incident Technique (сіт) (Flanagan 1954). Interviewees were asked to identify and describe the critical incidents, as well as the consequences of those critical incidents for the business. A critical incident is an extreme behaviour, either outstandingly effective or ineffective with respect to achieving the general aims of the activity (Fisher and Oulton 1999). 
All the interviews were audio-recorded and fully transcribed. The analysis of the data was based on a careful and continuous rereading of the interviews. The data analysis was crosschecked by at least two researchers to obtain reliability.

Sweden and Finland are selected as the context environments of this present study because of interesting aspects related to their eHealth service business. The Swedish healthcare system is considered a model for other countries (OECD 2013), and Sweden advanced considerably in enabling the latest digital technologies to enhance productivity and innovation (World Economic Forum 2014). Finland is known for its high technology and it is one of the leading countries in digital performance globally. The ranking of the Digital Economy and Society Index (DESI) evaluation shows Sweden and Finland are leading countries at the global stage. The top-three performing $\mathrm{EU}$ countries are Sweden, Denmark and Finland (European Commission 2016). In addition, both countries are considered among the most innovative countries in the world, with Sweden being ranked second and Finland fifth (Dutta, Lanvin, and Wunsch-Vincent 2016). Therefore, we are justified in taking a closer look at eHealth service start-ups in the Nordic - more precisely Swedish and Finnish context.

\section{Results}

Based on the interviews, many positive and negative incidents emerged from the data. This paper represents the recalled incidents related to development of eHealth companies. In this results section, the identified eight themes of positive and negative critical incidents were classified from the data, namely:

- Human resources

- Marketing

- Financial resources

- External relations

- Regulations

- Decision making

- Development and delivery of services

- External support

HUMAN RESOURCES

The positive incidents that emerged were often related to staff and successful recruitment. Great developers, the first successful recruitments and multi-professional expertise in core teams are fac- 
tors highlighted in terms of the developing of start-ups. A committed, experienced and reliable staff is considered extremely vital - the team must work well together.

Those who work for us, they don't have any specific working hours but they work like hell and they are not stressed because this is rewarding all the time.

Previous experience with entrepreneurship helps during the startup stage. In addition, a staff with good references is important, particularly because previous references are expected to have in cooperation with the public sector.

References are always needed. Because some of us were wellknown already before, so they know who we are, what this means and what we stand for.

Combinations of various competencies and a clear division of responsibilities between co-founders or between staff members were cited as positive incidents in many cases. A key positive critical incident seems to be that recruitment has been successful. In addition, in successful cases, much effort has been focused on increasing staff wellbeing. It could build a positive image as an employer, and this may affect the commitment of the staff.

On the other hand, negative incidents related to staff were revealed from the data. The personal relationships between owners and possible conflicts could be turning points of start-ups. In one case of a start-up, because of a conflict between founders, new arrangements regarding ownership were made. In effect, growth of this business was delayed. Recruitment problems are related to the inability to find competent and motivated employees for a start-up.

I would definitely say that in the start-up phase, we recruited people and started to collaborate with people that were not right for the company.

In terms of growth management, negative incidents could emerge because during the start-up phase, everyone is completing many tasks and it becomes challenging to measure the results of the work. The recruitment of competent employees may be difficult as a startup if job seekers perceive the company as risky. The most qualified employees have higher expectations regarding salary, as well.

It is difficult for small companies to attract competent workers. It is difficult to pay them enough. We also have very bad option possibilities in Sweden. 
MARKETING

Managers' experiences related to marketing appear clearly from the data. Customers' needs and willingness to accept new eHealth technology are crucial parts of success. From a manager's perspective, a positive incident often occurs when a start-up gets its first paying customer in the early stage.

It was extremely good for us to have a real customer, so we didn't just develop something off the top of our head or the way we imagined it.

According to one start-up manager, an early customer can provide a proof a concept, which makes it much easier to attract other investors. One of the most important issues is to get in contact with care units and to convince them of the new technology.

Our most significant thing was that we got our pilot product for use right there in a public health care organisation.

Customer feedback is considered an important factor for start-ups. Based on the feedback, services can been developed further.

We went courageously to seek feedback from customers and apply them on pilot customers.

In addition to positive incidents, negative incidents related to marketing were revealed from the interviews. Local healthcare authorities, such as county councils, play a strong role in deciding which medical products, technologies and services are provided to end consumers. A small start-up has significantly fewer resources with which to compete against large international corporations, although getting attention and being accepted is crucial for their development. The resistance to try new technologies is regarded as common in public healthcare. Even if new eHealth technologies are provided free for test use, their implementation is difficult. The interviewees have the perception that healthcare actors are afraid of new technologies and implementing new ways to offer services. Care units and personnel are highly focused on their daily tasks, and implementing a new technology is not common practice.

It is very symptomatic for the healthcare sector that you are very busy with your own thing and external things [...] The view of what a customer wants is forgotten.

In addition, incentives to develop and make services more effective are missing. Besides, the presence of constant surveillance and quality checking has been lacking in traditional healthcare. Success in public procurements and framework agreements with contracting 
entities are essential to the survival of a newly established eHealth start-up.

The biggest challenges are these framework agreements and procurements. As a new company, we don't have our own framework agreements and thus, we are dependent on other companies. We must work as consultants to them.

Previous references of successful contracts are a prerequisite for working with the public sector. Moreover, a lack of long-term procurement agreements leads to insecurity in hiring new employees. According to some eHealth start-up managers, doctors play a dominating role in decision-making within care units.

The newness of eHealth technology puts companies in a situation where they must take responsibility for educating both users and financiers. For instance, online shopping sets certain requirements for customers' technological capabilities. Persistence to convince customers and to make a start-up succeed is needed from the entrepreneur.

We must educate both the consumers and society. Both. That's what we have had trouble with.

Success in start-up competitions is a way to gain funding and visibility, as well as to create networks. According to one case company, networking can be more successful when somebody has heard of or read about you in the newspaper.

I think it's very important to meet people and to have these different experiences and education.

In some cases, visibility through start-up competitions has opened doors. Success in a start-up, as well as invention competitions and media visibility, help to give a business a head start. In addition, media visibility of the start-up culture has been a positive contributor to businesses.

We had a lot of media attention in the beginning. We had a rocket start and since then we've had stable growth.

To meet with the units, talk with them [...] to ensure they know us, see us and hear us.

However, negative incidents related to awareness of eHealth business emerged from the interviews. A major challenge is that society is still unfamiliar with the sector. As a small start-up, it is difficult to compete against large companies in obtaining visibility. The public sector is unaware of the eHealth solutions small enterprises could provide. 


\section{Financial Resources}

Financial resources are one of the main themes of eHealth start-ups. Typically, positive incidents related to funding are turning points of their growth.

I think it's very difficult to get the first investor, and that had quite a big influence, I think, because it's now much easier to get the second one.

Getting the first investor in the early stages helps to develop the technology further into forms that are more sophisticated. The psychological importance of private investors was also highlighted. Start-up entrepreneurs perceive it as encouraging having an investor who believes in their business. The role of the public sector as a funding actor (e.g. Vinnova, Tekes) was recognised as an important promoter of eHealth start-up businesses.

Public funding has played an important role, because commercial customers have come slower than planned, so public funding has saved us in the way.

On the other hand, managers' experiences related to funding also emerged in a negative light. The lack of resources during the startup stage is mentioned by nearly all cases. Therefore, external funding is required when challenges related to cash flow and revenues arise. However, external funding is not necessarily available. Banks and other potential financiers are unfamiliar with eHealth technology and they are unsure of how to tackle a new type of business.

In a country like Sweden, it is basically impossible to hire someone to be paid for or to get bank loan. Therefore, we have put our own time on this. Evenings and nights and weekends.

And the banks will not grant funding; nowadays the situation is so tight. So, it is very difficult to get anything from the banks, because these kinds of start-up companies do not have real guarantees.

Getting financing for new technology development is not necessarily easy. If other funding sources are not available, start-up owners may have to use their own savings.

We built the first platform to show up. We did it with our own wallet. We kept it very tight.

In addition, business development during the early stage is difficult because of the discontinuity and fragmentation of funding. The focus of start-up managers' operations has been on seeking and applying funding more than on business development. 
Start-ups consider cooperation and networking important elements for growth. In the healthcare sector, partnerships with bigger companies may open doors to close collaborations with practical care units. Moreover, cooperation with public sector actors is recognised as playing a key role in business in many cases. Start-up managers perceived cooperation with other companies in the same industry as a positive driver. Synergy is perceived positive, for example, in the business hubs of the health sector. Based on the interviews, positive incidents emerged when the interactions between different healthcare actors and the company were successful.

Dialogue with operators in the field is essential.

We have indeed achieved trust among such greater partners, big players [...] that they rely on a start-up company.

In addition, positive incidents arise when cooperation with research institutions is achieved. Obtaining research-based information about the effectiveness and benefits of a service or product is a prerequisite for action in the field of health services. The meaning of research-based credibility is central to the whole business.

\section{REGULATIONS}

The legal matters surrounding eHealth cause challenges. Because the sector is new, practices of the authorities lag behind. Many negative incidents related to regulations were revealed from the data. Start-ups consider legislation and quality standards strict for healthcare businesses. Furthermore, legislation regarding eHealth is to a large extent missing. On the other hand, the healthcare sector is strictly controlled by legislation, and technical requirements for innovations must be properly met. Ehealth technology differs from traditional technology, because it is alterable and includes new features that cannot be measured using old standards.

What we really had needed all the time is help with the legal matters related to eHealth, because this is new. You must find a right partner to work with and it is very expensive.

In addition, bureaucracy causes troubles for eHealth start-ups. Official processes take a long time. New eHealth solutions may be falsely categorised among other alternative products and technologies, some of which are even regarded as illegal or whose legal status is at least questionable. Information and guidelines concerning applicable certifications are insufficient. Furthermore, certification 
requirements have been prepared for existing static products and services.

We have lost our efficiency to develop things quickly, partly because of these wait times and partly because of the lack of legislation for these kinds of products.

\section{DECISION MAKING}

In many cases, managers perceived companies' internal practices having influenced positively start-up growth. Data revealed that positive incidents occur when decision-making and ownership are separated at a very early stage. Plans to grow and reach new markets have been an integral part of quickly growing start-ups.

We have concrete plans to get into new countries. This product will be completed and further developed.

A small co-founder team, wherein each team member has focused on different task areas based on their strengths and each member has clear shared responsibilities for his or her own sector, are seen as positive incidents during the early stages of a business. Moreover, the successful delegation of tasks, a clear mode of operation and shared ownership arrangements are perceived positively.

\section{DEVELOPMENT AND DELIVERY OF SERVICES}

Some interviewees had a positive experience with developing a minimum viable product for reasonably low costs.

It is quite simple to get started, to make the first minimum viable product.

Developing proper contracts with the subscriber is important. A new start-up is eager to get started, and sometimes agreement matters remain in the background until something unexpected and unwanted occurs. Based on the interviews, the general slowness of the development of a product-related service was identified as a negative incident. Operating in new industry takes much time. Moreover, production costs are considered high.

In Finland, when making an industrial product [related to service], the manufacturing cost is indeed quite staggering.

Because eHealth start-up services are typically linked to a technology product, the development stage takes time. 
Saarela et al.

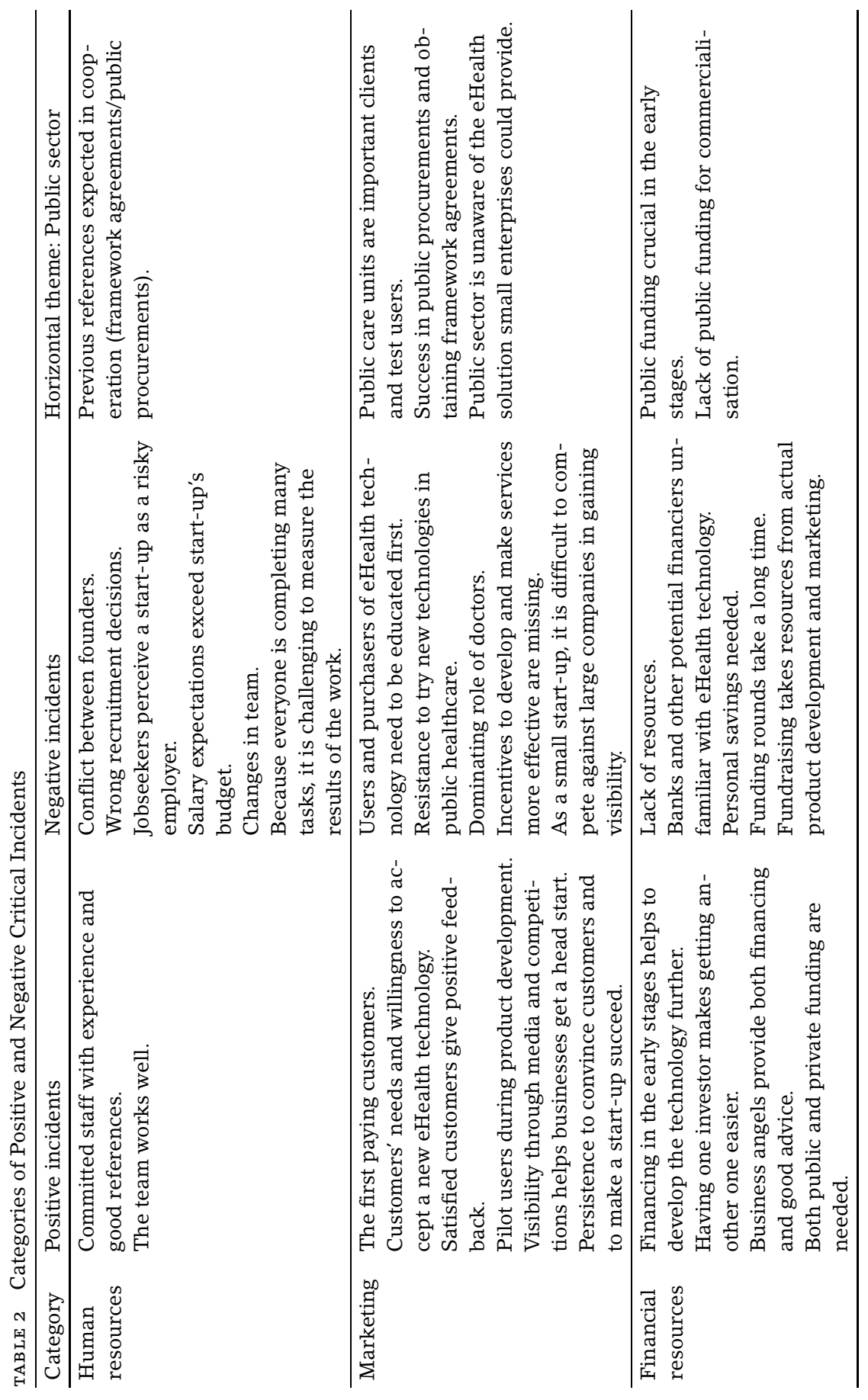


Critical Incidents of Growth

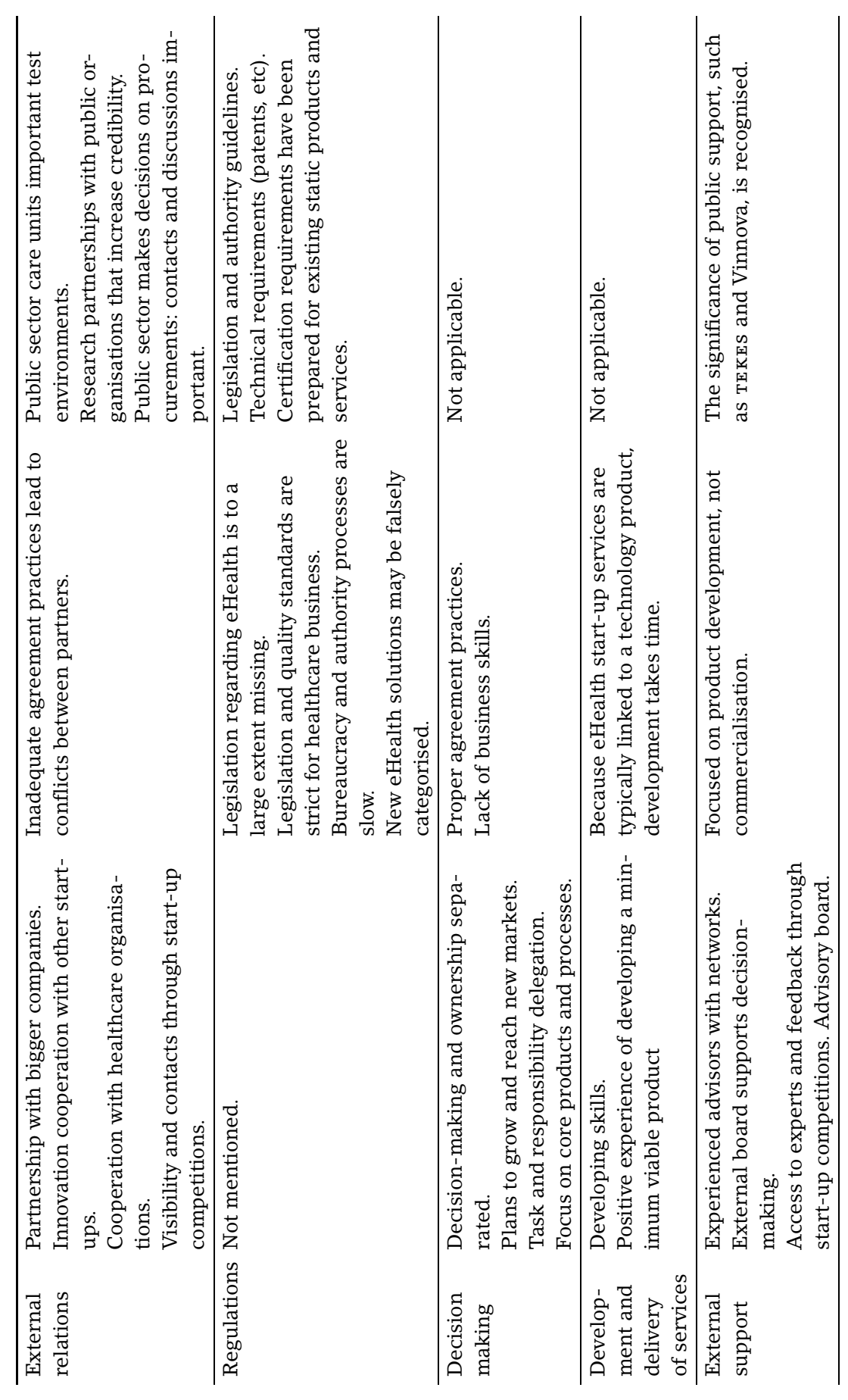


Managers' perceived positive incidents were often associated with external support. Cases utilised expert services to focus activities and build strategy. To develop strategy planning, the start-ups utilised, for example, an advisory board or incubators. To foster strategy development, a variety of experts and feedback through start-up competitions were utilised. Experienced advisors with networks in the industry are important for eHealth start-ups.

We have two or three advisors who have long experience in the med-tech industry and also medical industry.

I think this incubator is quite good too, because they have a large network and connections.

In some cases, negative incidents occur due to a lack of public support related to the commercialisation of services. Particularly in Finland, public funding is targeted more at product development than at commercialisation.

\section{Discussion}

With this study, we identified the themes of positive and negative critical incidents in the context of Nordic eHealth service start-ups. Start-ups consider themselves ahead of their time, and the industry is still narrow. Because eHealth start-up services are typically linked to a technology product, developing product-related services takes time. Even if the start-up already has early customers, the income level is not sufficient to ensure profitability. The start-up stage is financed mainly by investment funding, personal savings and public support.

Several recalled critical incidents are related to the public sector. Table 2 (pp. 126-127) provides a summary of the categorised critical incidents. The public sector plays an essential role in the healthcare industry, both in positive and negative terms. However, the role of public actors is strongly connected to whether they are customers of the start-up. In Nordic countries, a major portion of the healthcare business is produced via public procurement. However, startups perceived themselves as having difficulties in setting up public contracts. In calls for tender, contracting entities require references and capacities that start-up businesses do not usually have yet. To highlight the importance of the public sector, it is presented as a horizontal theme across the categories related to critical incidents in table 2 . The categories formed include human resources, marketing, 
financial resources, external relations, regulations, decision-making, development and delivery of services and external support.

The main themes identified in this study seem to be in accordance with the main themes derived from the stages of growth theories about the start-up stage of a service-based firm (See Muhos et al. 2017). The similar themes include human resources, marketing, financial resources, decision-making, development, and delivery of services. However, in this context, one theme was identified: the regulations. In the context of eHealth business, the business environment is heavily regulated, and it is important for eHealth start-ups to cope with the challenges and opportunities of this environment.

The research focus of this study is limited to the context studied. The findings of the study cannot be directly generalised to other countries or business contexts and they depend on the time of data collection. Implementing this analysis in other business contexts would make an interesting study.

\section{References}

Agarwal, R., G. Gao, C. DesRoches, and A. K. Jha. 2010. 'The Digital Transformation of Healthcare: Current Status and the Road Ahead.' Information Systems Research 21 (4): 769-809.

Barnett, J., K. Vasileiou, F. Djemil, L. Brooks, and T. Young. 2011. 'Understanding Innovators' Experiences of Barriers and Facilitators in Implementation and Diffusion of Healthcare Service Innovations: A Qualitative Study.' вмс Health Services Research 11 (342). doi:10.1186/1472-6963-11-342

Berwick, D. M. 2003. 'Disseminating Innovations in Health Care.' Journal of the American Medical Association 289 (15): 1969-75.

Chen, S.-H., P.-C. Wen, and C.-K Yang. 2014. 'Business Concepts of Systemic Service Innovations in E-Healthcare.' Technovation 34 (9): $513^{-24}$.

Chowdhury, J. 2012. 'Hacking Health: Bottom-up Innovation for Healthcare.' Technology Innovation Management Review 2 (7): 31-5.

Dutta, S., B. Lanvin, and S. Wunsch-Vincent, eds. 2016. The Global Innovation Index 2016: Winning with Global Innovation. Ithaca, NY: Cornell University; Fontainebleau: INSEAD; Geneva: wıPo.

European Commission. 2012. 'eHealth Action Plan 2012-2020: Frequently Asked Questions.' Memo/12/959, European Commission, Brussels.

_. 2015. 'A Digital Single Market Strategy for Europe.' сом/2015 10192, European Commission, Brussels.

- 2016. International Digital Economy and Society Index: Final Report. Brussels: European Commission. 
Fisher, S., and T. Oulton. 1999. 'The critical Incident Technique in Library and Information Management Research.' Education for Information 17 (2): 113-25.

Flanagan, J. C. 1954. 'The Critical Incident Technique.' Psychological Bulletin 51 (4): 327-58.

Freeman, J., G. R. Carroll, and M. T. Hannan. 1983. 'The Liability of Newness: Age Dependence in Organizational Death Rates.' American Sociology Review 48:692-710.

Haltiwanger, J., R. Jarmin, and J. Miranda. 2013. 'Who Creates Jobs? Small versus Large versus Young.' The Review of Economics and Statistics 95 (2): 347-61.

Lumpkin, G. T., and G. G. Dess 1996. 'Clarifying the Entrepreneurial Orientation Construct and Linking it to Performance.' Academy of Management Review 21 (1): 135-72.

Muhos, M., A. Simunaniemi, M. Saarela, D. Foit Jr., and L. Rasochova. 2017. 'Early Stages of Service Business: Review and Synthesis.' International Journal of Management and Enterprise Development 16 (3): 151-73.

Nanda, R., and M. Rhodes-Kropf. 2013. 'Investment Cycles and Startup Innovation.' Journal of Financial Economics 110 (2): 403-18.

Neergaard, H., and J. P. Ulhoi. 2007. 'Introduction: Methodological Variety in Entrepreneurship Research.' In Handbook of Qualitative Research Methods in Entrepreneurship, edited by H. Neergaard and J. P. Ulhoi, 1-16. Cheltenham: Edward Elgar.

Nooteboom, B. 1994. 'Innovation and Diffusion in Small Firms: Theory and Evidence.' Small Business Economics 6 (5): 327-47.

oEcD. 2013. овcD Reviews of Health Care Quality: Sweden 2013. Paris: Organisation for Economic Co-Operation and Development.

- 2015. Health at a Glance 2015: овcD Indicators. Paris: Organisation for Economic Co-Operation and Development.

Parente, S. T. 2000. 'Beyond the Hype: A Taxonomy of E-Health Business Models.' Health Affairs 19 (6): 89-102.

Pinto, R., and M. Baracsi. 2012. 'Creating an Environment for Innovative Start-Ups in Healthcare.' Health Policy and Technology 1 (4): 187-92.

Rocha, A., A. Martins, J. Celso Freire Jr., M. N. Kamel Boulos, M. Escriche Vicente, R. Feld, P. van de Ven, J. Nelson, A. Bourke, G. Laighin, C. Sdogati, A. Jobes, L. Narvaiza, and A. RodriguezMolinero. 2013. 'Innovations in Health Care Services: The cAALyx System.' International Journal of Medical Informatics 82 (11): 307320.

Rosenbusch, N., J. Brinckmann, and A. Bausch. 2011. 'Is Innovation Always Beneficial? A Meta-Analysis of the Relationship between Innovation and Performance in smes.' Journal of Business Venturing $26(4): 441-57$.

Samuelsson, M., and P. Davidsson. 2009. 'Does Venture Opportunity 
Variation Matter? Investigating Systematic Process Differences between Innovative and Imitative New Ventures.' Small Business Economics 33 (2): 229-55.

Stinchcombe, A. L. 1965. 'Social Structure and Organizations.' In Handbook of Organizations, edited by J. G. March, 142-93. Chicago: Rand McNally \& Company.

Van Limburg, M., J. E. van Gemert-Pijnen, N. Nijland, H. C. Ossebaard, R. M. Hendrix, and E. R. Seydel. 2011. 'Why Business Modeling is Crucial in the Development of eHealth Technologies.' Journal of Medical Internet Research 13 (4): e124. doi:10.2196/jmir.1674

World Economic Forum. 2014. The Europe 2020 Competitiveness Report: Building a More Competitive Europe. Geneva: World Economic Forum.

Yin, R. K. 1989. Case Study Research. Beverly Hills, cA: Sage.

This paper is published under the terms of the Attribution-

NonCommercial-NoDerivatives 4.o International (CC BY-NC-ND 4.0)

License (http://creativecommons.org/licenses/by-nc-nd/4.o/). 